\section{Contributed Papers}

\author{
Crop Production Practices (W. Charles Wal-
} den, University of Arkansas)

\begin{abstract}
"Economic Implications of Alternative Cotton Production Practices: Texas Lower Rio Grande Valley." Glen S. Collins, Ronald D. Lacewell and John Norman, Texas A\&M University.

On light to medium textured soils in the Lower-Rio Grande Valley of Texas, dryland cotton production is more profitable than irrigated (\$108 compared to $\$ 25$ per acre return above variable costs).

Dryland short-season cotton production is associated with a greater per acre net return than either conventional cotton production techniques or use of irrigation. In addition, risk, as measured by the coefficient of variation for yield, is least for dryland short-season cotton production. There are dramatic energy, environmental and farmer profit implications associated with the very low input short-season cotton production system.
\end{abstract}

"A Labor/Energy Production Function for Tomatoes in North Florida." Edward Canler, W. Arden Colette and Bryan E. Melton, University of Florida.

Observations on labor and energy use in tomato experimental plots conducted at the University of Florida Horticultural Unit in Gainesville area used to develop a labor/energy production function for tomatoes. Ordinary least squares procedures are used to estimate the parameters of the function. A quadratic function in labor, energy and planting date provided the best fit to the data while conforming to the biological characteristics of the crops. The analysis of input use derived from the production function indicates that energy is used at a level beyond its economic optimum. The production analysis also indicates that as planting date is delayed during the spring season both more energy and more labor input are required to maintain output levels.

"On Crop Response to Lime in the Tennessee Valley Region." Harry H. Hall, University of Kentucky and W. Joe Free, TVA, Muscle Shoals, Alabama.

Excessive soil acidity has long been recognized as one reason soils become unproductive, and liming to correct excessive acidity has been practiced at least since the second century B.C. This analysis assumes that farmers who choose production inputs economically are willing to increase their lime rates so long as the value of increased production (or reduction in the cost of other inputs) exceeds the cost of the lime. Unless lime increases crop yield or reduces the quantity of other inputs required, there is no economic reason to use it. A response-surface formulation of crop-response to lime is reported. Responses for alfalfa and corn are approximated by grafted polynomials, also called spline functions.

"Estimation of Crop Water Response and Economic Optimization for Continuously Growing Crops." Gary D. Lynne, Robert Solove and Bryan E. Melton, University of Florida.

Further insight is provided regarding an appropriate model of cropwater response for continuously growing crops. A dated input production function was estimated for pineapple oranges in Florida. Generalized least squares regression techniques were used to ameliorate the effects of contemporaneously and serially correlated errors. The continuously growing citrus crops also lead to factorially determined production relations over time. This causes the economic optimum level of water to apply in any given time period to be a function of water applied in the past and expectations for the future.

Livestock Prices and Futures (John R. Franzmann Oklahoma State University)

"A U.S. Regional Model of Feeder Steer-Heifer Price Differentials." Steven T. Buccola, Virginia Polytechnic Institute and State University and David L. Jessee, W. R. Grace and Co., Wilmington, North Carolina.

Concern is frequently expressed that market price differentials between feeder steers and heifers do not reflect fundamental supply and demand factors, and that mean regional variations in the differentials are not justified. The present study investigates these issues by: (a) constructing a market model of quantity and price differences for feeder steers and heifers, (b) utilizing firm profit models to develop hypotheses for the market model's reduced form, and (c) subjecting the reduced form to statistical analysis. 
It is hypothesized that slaughter steer-heifer price spreads, feed prices, hay prices, the shortrun rate of change in feeder steer prices, and the proportion of steers to total cattle on feed positively affect price premiums on feeder steers over feeder heifers. These effects are tested by identifying cattle producing and feeding regions in the U.S. and developing annual data at representative market points for the years 1964-76.

Statistical results strongly support the hypothesized relations. Hay prices and the proportion of steers on feed have, in an elasticity sense, the greatest impact on the feeder steer-heifer price spread. Farmer profitability factors appear just as important as feedlot profitability factors. There is some evidence of pricing inefficiency in feeder cattle markets, but this conclusion is tentative in the absence of additional information.

"The Response of Futures Prices to New Market Information: The Case of Live Hogs." Stephen E. Miller, Clemson University.

Most previous studies of futures market efficiency have analyzed the adjustment of futures prices to general kinds of new supply and demand information. Research related to the response of futures prices, particularly those for livestock, to specific kinds of new information is scarce. This study analyzes the adjustment of live hog futures prices to a specific kind of new information; the new information concerning potential slaughter hog supply implicit in the sow farrowing data of the USDA's Hogs and Pigs Report.

"Risk Ratios and Hedging: Florida Feeder Cattle." Ronald W. Ward and Gregory E. Schimkat, University of Florida.

The feed cattle industry has expanded in the southeast and especially in Florida. Price risk for Florida producers tends to be higher than midwestern producers. A comparison of relative risk rations with and without hedging shows that the feeder cattle contract can be effective for Florida producers. However, the degree of effectiveness changes with feeder weights, grades, location and initial hedging prices.

"An Economic Evaluation of the Use of Oscillators as Decision Guides in Hedging Feeder Cattle." James R. Russell and John R. Franzmann, Oklahoma State University.

In recent years, the high variance of feeder cattle prices has subjected the cattle industry to large price risks. Selectively shifting these 176 price risks to another through hedging has the potential of both decreasing the variance and increasing the magnitude of returns to the decision maker.

This study develops feeder cattle hedging strategies based on oscillators. Over 150 oscillator combinations, which utilized five different oscillator models, were tested across fourteen feeder cattle contracts. The model which used the crossing of two oscillators in developing buy and sell signals, created the largest trading profits. These tested oscillators were then evaluated as decision aids in the short hedging of feeder cattle across three production alternatives. Similarly, using a 180-day planning horizon the oscillator technique was tested for the long hedge. In both hedging situations, the use of oscillators as decision guides increased the magnitude and reduced the variance of returns. Selective hedging based on this tool should be of benefit to the feeder cattle producer and cattle feeder.

Agricultural Policy and Programs (W. W. McPherson, University of Florida)

"Impacts of Agricultural Research and Extension on Agricultural Output in the Southern Region." Fred C. White and Joseph Havlicek, Jr., Virginia Polytechnic Institute and State University.

Increases in agricultural productivity in the Southern region arise from many sourcesboth within the region and outside the region. However, the interregional transfer of research results has generally been ignored is previous research which evaluated the returns to agricultural research and extension investments. The results in this study demonstrate that failure to account for interregional transfers would exaggerate the returns to regional research and extension investments. Attributing all increases in productivity in the Southern region to research and extension investments within the region results in a 72 percent internal rate of return. After accounting for the interregional transfer of research results, the return on research and extension investment in the Southern region drops to 20 percent. Even after correcting for the interregional transfer of research results, investment in research and extension is still an attractive investment for the Southern region. These results also demonstrate that regions initiating research and extension activities are not the only beneficiaries of the results. The social returns to these regional investments include higher productivity in other regions and lower prices for consumers. 
"Optimal Control of Agricultural Production Research and Extension Expenditures." James Shouse, James Trapp and Luther Tweeten, Oklahoma State University.

Optimal control procedures are applied with a model of U.S. agricultúral productivity to determine a time path of public research and extension expenditures $(R)$ required to achieve a specified internal rate of return on investment. Rates of return on $R$ outlays historically have been high in relation to rates on other investment, suggesting the need to increase outlays. Based on previously estimated functions relating agricultural productivity to investments in research and extension, an objective function was specified to minimize the difference between the achieved internal rate of return and the desired internal rate of return. A five equation form of the model was run over a 50 year period beginning in 1977 . To achieve a more economically efficient allocation of public investment in research and extension requires increasing real outlays by 10 percent annually for 8 years if the demand for farm output is growing 1.5 percent per year and for 12 years if demand is growing at 2.1 percent per year. Thereafter the rate of growth in research and extension outlays is reduced to near the rate of growth in demand for agricultural products.

"An Analysis of the 1979 Feed Grain SetAside Program." Thomas M. Bell, NEAD, ESCS, USDA, Joe Roop, NEAD, ESCS, USDA, and Lloyd E. Teigen, CED, ESCS, USDA, Washington, D.C.

Five program choices are examined regarding feed grain and cotton set-aside and diversion, given the 20 percent set-aside for wheat. The acreage response to these programs are translated into prices and quantities for the major commodities via impact multipliers derived from USDA's Cross-Commodity Forecasting System. The prices and quantities are then translated into measure of agricultural aggregates such as farm income, farm prices received indexes, farm-retail spreads, and retail food prices. A 15-percent set-aside with 15 percent diversion for feed grains would have the most impact; food prices under the $10 \%$ set-aside only alternative would rise one-third of one percent based on our calculations.

"Impacts of Market Policies on Risk in Farm Net Income." Joe Roetheli, TVA, Muscle Shoals, Alabama and Kenneth Schneeberger, University of Missouri.

Market intervention policies for crops have important risk implications for farmers. An aggregate linear programming framework incorporating risk via the MOTAD framework was constructed for crops produced in Northwest- ern Missouri. A free market policy, price stability program, and yield stability scenario were delineated and analyzed relative to alternative risk levels. The free market scenario was less risky than a program of complete price stability. Based on conditions in NW Missouri for 1973-77, cash-flow problems were less severe with a free market than with stable prices. Yield contributes more instability than price to net income from crops.

Land, Water and Energy (Burl F. Long, Virginia Polytechnic Institute \& State University)

"An Analysis of Land Clearing an Eastern North Carolina Wetlands." Ralph Heimlich, Clayton W. Ogg and John E. Hostetler, NRED, ESCS, USDA, Broomall, Pennsylvania.

The probable location of future additions to cropland in North Carolina's coastal plain is related to commodity price trends, potential productivity of soils, and existing land use. Map overlays of sampled 1967-1974 land use on soils data confirm that hypothesized relationships between productive soil groups and conversion to cropland uses are important in explaining the location of new cropland. These relationships can aid in assessing the extent of probable future clearing and its impact on wildlife habitat. The timing of future clearing continues to be affected primarily by national and worldwide demands, however.

"Implication of Improved Irrigation Pumping Efficiency of Farmer Profit and Energy Use." Daniel C. Hardin and Ronald D. Lacewell, Texas A\&M University.

The average efficiency of an irrigation pump on the Texas High Plains is less than what could be achieved through timely repairs. A recursive linear programming model is used to estimate changes in returns to groundwater, by distribution system and aquifer situation, resulting from the use of more efficient pumps.

"Energy: The Farmer's New Foe." Joel S. Williams and Ralph Kline, Virginia Polytechnic Institute and State University.

Availability and price of energy has become an important factor in farm decisions today. Returns to management are compared for various energy uses and energy price levels using a typical Grade-A dairy farm. Returns from notill corn production were higher than for conventional tillage, and a liquid manure system generally produced higher returns than a solid manure system. It appears that a reduction in energy supplies reduces returns to management more than equivalent increase in energy 
prices. Farmers need to give consideration to these issues to develop successful farm plans.

"Farm Size and Rural Communities: Some Economic Relationships." Gerald Marousek, University of Idaho.

The economic impacts of farm size alternatives on a rural community were assessed by (1) deriving empirical measures of the relative economic importance of small and large farms and (2) estimating the income, output and employment effects of various farm size structures. Input-output analysis was used to determine the economic structure of the community. Then multiplier analysis and consistent forecasting were applied to establish the effects of changes in farm size structure. The economic trade-off brought into focus is essentially between income and employment. Displacement of small farms by large farms results in greater regional income while increasing the number of small farms yields greater regional employment. Agricultural output is comparable for the two farm size structures. A wide range of policy alternatives is suggested by these results. At one extreme, the process of economic change which results in fewer and larger farms, rural to urban outmigration and declining rural towns can be accepted as socially desirable. At the other extreme, the continued existence of viable small farms and rural communities can be accepted as worthy in and of itself. The relative merits of these extreme positions and various alternatives between them cannot be assessed by economic analysis alone.

Livestock Production Systems (John W. Hubbard, Clemson University)

"Computer Simulation of Silage-Based Cattle
Feeding Under Southeastern U.S. Conditions." Fred H. Tyner, David H. Laughlin, H. Werner Essig and W. Roy Burris, Mississippi State University.

Backgrounding systems to supplement the basis cow-calf operations in Mississippi are expanding, but few cattle are being fed to slaughter weight. Finishing cattle on silagebased rations offers an opportunity to capitalize on the number of "feedlot-ready" cattle produced in the state and on the potential for harvesting high yields of energy per acre in the form of corn silage - the Mississippi and other southeastern states.

This paper reports a computer program which simulates the feeding process in a feedlot situation. The program allows the user to describe cattle to be fed (number, body type, weight, age, sex, desired or potential rate of gain, and desired ending weight); computes nutritional requirements (protein and energy) for these cattle; formulates a least cost silagebased ration to meet the calculated nutritional requirements and other user-specified nutrient restrictions; calculates expected performance (rate of gain) of the cattle; and provides a report which shows (for each month or partmonth in the feeding period) the ration content, batch weight, cost per batch, number of batches per day, weight gain, consumption per head, feed cost per head and total, feed cost per pound of gain, and feed ingredient totals. A summary report which covers the entire finishing period is also prepared.

Such modeling of the feeding process serves to extend the use of results obtained through interdisciplinary research, helps to identify additional research needs, and provides a "package" of results to enhance the useability of experimental results for decision making by producers.

"A Systems Analysis of Fed Beef Production and Marketing." Wayne M. Gauthier, Louisiana State University and Wayne D. Purcell, Virginia Polytechnic Institute and State University.

The economic benefits of a coordinated type and fed weight production program for the subsystems of the fed beef system were illustrated using the results of a profit-maximizing linear programming model. The criteria for analysis of four independent subsystems and an integrated system were level of returns and product complementarity between producing and using subsystems. Low energy, high energy, and compensatory gain growth situations for Jersey-Angus (JRAN), Hereford (HERE), and Charolais-Hereford (CHHE) types were structured for analyses of the independent cow-calf, stocker, feeder, packer and breaker subsystems and integrated system.

Under 1974 conditions, optimum coordination did not prevail among the independent subsystems. The cow-calf subsystem optimized through production and sale of a JRAN calf. The stocker and feeder subsystems optimized with inactivity. The packer and breaker subsystems optimized with a 1261 pound $\mathrm{CHHE}$. Comparatively, the integrated system optimized with a coordinated production, feeding, slaughtering and breaking program for a 1074 pound $\mathrm{CHHE}$.

Parametric analyses indicated that the patterns of adjustment in feeding regime, fed weight, and/or type to increasing grain prices differed among and between the subsystems and integrated system. The days on low energy feeding increased withrincreases in grain prices for all feeding programs, but low energy feeding to slaughter weights never materialized in any feeding program. 
"Optimum Rations and Rates of Average Daily Gain for Stocker and Finishing Steers with Broiler Litter." Ronald J. Waller and James $\mathbf{O}$. Wise, University of Georgia, Athens.

This study explored the possibilities of feeding broiler litter to stocker and finishing animals at various levels. Four trials were conducted using ensiled broiler litter as 50, 60, 70, and 80 percent of the stocker ration and broiler litter as 25 percent of the finishing ration. Other cattle feeds were used in combination with broiler litter, and also as alternatives to broiler litter. The steer's feed requirements were expressed as Total Digestible Nutrients (TDN), and the steers were fed at various rates of gain. Stocker steers were analyzed at rates of gain of $1.0,1.25,1.5,1.75$, and 2.0 pounds per day, while feeder steers were analyzed at rates of gain of 2.0,2.25,2.50,2.75, and 3.0 pounds per day. The study was based on a feedlot capacity of 1000 steers. Optimum rations indicated that broiler litter was a cheeper source of feed for cattle production operations than the alternatives considered in this analysis.

"An Economic Analysis of Farrow-To-Finish Swine Enterprises in Kentucky." Marvin T. Batte, University of Kentucky and Fred E. Justus, University of Kentucky.

The purpose of this study was to determine the major factors influencing costs and returns of farrow-to-finish swine enterprises in Kentucky. Physical and financial records of $64 \mathrm{en}-$ terprises in 1976 were analyzed. Two multiple regression models were obtained. Regressing seven independent variables on total cost per cwt. of production gave a model that explained 75 percent $\left(R^{2}=.759\right)$ of total variation in cost of production, and was statistically significant at the 0.01 probability level. Five variables were significant at the 0.05 percent level; pounds of feed per cwt. production, cost of concentrates, investment per litter, death loss and pigs farrowed per litter. Labor used per litter and number of litters farrowed were not significant.

Regressing these seven variables, plus price received for hogs sold on net return per cwt. of production gave a model that explained 77 percent of net return variation $\left(\mathrm{R}^{2}=0.770\right)$. The model was significant at the 0.01 probability level. Of the independent variables analyzed, only enterprise size (litters farrowed) was not significant at 0.05 percent level. Most results are in general agreement with hypothesized relationships. Lack of support for conceptualized economies of scale suggests that these economies are not automatic for an indivdual considering expansion.
Crop Marketing Performance (Floyd W. Williams, University of Georgia)

"Changes in Price Patterns of North Carolina Soybeans and Corn." Mike Ryall and Ronald A. Schrimper, North Carolina State University.

This study was designed to determine if the seasonal pattern of cash farm prices for soybeans and corn in North Carolina has been changing. A second issue consisted of empirically determining the difference resulting from use of the simple seasonal average procedure rather than the more complicated moving average techniques for contrasting seasonal price indices. The results indicated slightly larger seasonal price discounts during harvest and winter months but higher premiums in late summer for soybeans during the last five years compared to earlier years. On the other hand, the most significant change in the seasonal price pattern for corn is that, during the last five years, prices have been relatively stable from January to May instead of continually rising as observed in earlier years. Comparing the empirical results of two alternative procedures for calculating seasonal indices indicated the seasonal average techniques exaggerated the amount of change within crop years relative to the results of using the moving average procedure. The contrast in results for the two procedures was larger during the last five years than the earlier period because of substantially higher inflation which is more effectively removed by moving average procedures.

"Efficient Interfacing of the Truck-To-Ship Intermodal Grain Transfer System: Port of Houston." Stephen Fuller and Mechel Paggi, Texas A\&M University.

The paper focuses on congestion problems arising in the truck-to-ship intermodal grain transfer system at the Port of Houston. Seasonal peaks in truck-delivered grain receipts creates problems with efficient interfacing of the port elevators' grain receiving capacity and truck arrival patterns. The purpose of this paper is to 1) quantify the magnitude of congestion cost, 2) estimate costs of reducing congestion to alternative levels, and 3) determine the least-cost level of congestion-reducing investment or conversely the optimum level of congestion to maximize efficiency. A stochastic network simulation model was constructed to carryout the queuing analysis. The analysis reveals congestion cost to be substantial and congestion-reducing investment in labor and capital economically feasible. It is hypothesized that most of the congestion cost is currently borne by the farmer via lower grain 
prices. The excessive congestion persists because of a market organization that allows congestion cost to be passed-on or not internalized by exporters.

"Influence of Market Diversification on Farm Income Variability of Soybean Producers." Bobby R. Eddleman and J. E. Moya-Rodriquez, Mississippi State University.

A parametric quadratic programming analysis is used to evaluate forward price contracting, open market sales and on-farm storage options for soybean producers facing market risks. Mean-variance analysis is used to derive sets of $\mathrm{E}-\mathrm{V}$ efficient marketing plans reflecting the influence of soybean price, yield, production costs, and on-farm storage cost variabilities on net income and income stability per acre. Results indicate that forward contracting about two-thirds of the crop prior to harvest and selling the remaining third on open market, or storing it on the farm for six months with open market and/or forward contract sales, provide the most stable net income per acre. Optimal marketing plans will include relatively high levels of forward contracting even for decision makers with little or no aversion to risk since profit possibilities based on expected contract prices appear to be greater than those based on expected market prices from open market sales.

"Simulation of Cotton Ginning Costs: Applications of An Economic-Engineering Model." Dale L. Shaw and Don E. Ethridge, Texas Tech University.

A computerized economic-engineering model was developed for estimating cotton ginning costs over a wide range of assumptions. $\mathrm{Re}$ sulting cost relationships may be useful for both policy analysis and providing information to the industry. This paper presents an overview of the model structure and the results of several applications. Application to selected situations demonstrates the model's capacity to analyze the economic impact of technological and regulatory changes on the cotton ginning industry and the capability to provide information relevant to firm management decisions.

Market Structure and Trade (John L. Adrian, Auburn University)

"Structure of the U.S. and West Texas Early Summer and Onion Markets." Bob Davis and Billy R. Hise, Texas Tech University.

Historically onion producers have seen large year-to-year fluctuations in price and production. The objective of this study was to explain the factors operating in the U.S. early summer onion market and the West Texas portion of the market which underly price and output determination.

Physical factors such as weather and technology influence acres planted, acres harvested, and yield per acre of onions both in West Texas and in the entire early summer market. Harvested acres times yield per acre equals total production, and production along with the production overlap from the late summer markets, population, income, and tastes and preferences of consumers affects the wholesale price for onions. The farm price is determined from the wholesale price and at the same time affects the wholesale price.

The farm price for last year's crop and last year's acres planted works-with cost of production and prices farmers expect to receive for alternative crops to determine planted acres of onions. A simultaneous model with four stochastic equations and two identities was developed to explain prices, quantities and acres harvested for West Texas and for the U.S. early summer onion markets. Yearly data for the period 1960-1975 were used to fit the model with 3SLS. The model was very close in predicting the acres of onions harvested and quantity, but less accurate in predicting price. However, tests of the model by computing Theil's inequality coefficients, turning point and overestimation errors indicate that it is superior to a naive no-change model in predicting values for the endogenous variables.

"Effects of New Carribean-Area Winter Fresh Tomato and Cucumber Supplies on the U.S. Industry." G. A. Zepp, CED, ESCS, USDA, University of Florida.

A spatial price and quantity equilibrium analysis was conducted to determine the effects of new tomato and cucumber supplies from Caribbean area countries on the vegetable industry. New supplies, equivalent to pre-1961 Cuban shipments to the U.S., would lower tomato prices by about $\$ .27$ and cucumber prices by $\$ .97$ per cwt. during the mid winter. Tomato production from the present supplying areas would decrease about 23.5 million pounds while cucumber production would be about 27.2 million pounds less. Total grower receipts would be $\$ 5.6$ million from cucumbers and $\$ 8.7$ million less from tomato sales. Mexico would bear the greater quantity adjustment because its export volume is largest during the mid-winter months when new Caribbean area supplies would be expected to arrive. Although Florida producers ship throughout the season, their largest volume shipping period occurs before and after the time when the bulk of Caribbean import would be expected. 
"Foreign Trade, Protection and Multinational Activity in U.S. Food Processing Industries." Emilio Pagoulatos and Robert Sorensen, University of Missouri, St. Louis.

This paper, drawing on the analytical framework of international trade and industrial organization, reviews and tests some new hypotheses concerning the effect of foreign trade, protection and foreign direct investment on domestic profitability of U.S. food processing industries. Our results suggest that foreign factors represent a fruitful addition to conventional structure variables in explaining interindustry differentials in price cost margins. Although the relationship appears to be complex, the greater the degree of actual or potential foreign competition the lower the price cost margins. In this regard it appears that tariff barriers and the exploitation of export opportunities have the most significant effects upon industry profitability. Furthermore, industries which have become more multi-national exhibit significantly higher domestic price cost margins.

"Benefits of a Sheep and Lamb Teleauction in Virginia and West Virginia." David L. Holder, CMPD, ESCS, USDA, Washington, D.C.

The farm-to-consumer marketing system for lamb is considerably less competitive and less efficient than the marketing systems for beef and pork. Much of the blame can be laid to declining sheep and lamb production.

Among the innovations likely to improve competition and efficiency of the producer-topacker segment of the system is the teleauction.

The teleauction of Eastern Lamb Producers Cooperative, Inc. has raised the general price level of lambs in Virginia-West Virginia by $\$ .70$ to $\$ 1.50$ a hundred pounds. The increase is the result of (1) increasing the number of local buyers from 1 to 10 , and (2) moving lambs to packers more efficiently. Another benefit of the teleauction is increased pricing efficiency.

However, the teleauction is not a panacea for marketing system problems. In spite of the teleauction, Virginia-West Virginia producers continue to lose their premium price position in comparison with major U.S. sheep and lamb markets because slaughter on the East Coast is declining so much faster than production.

Land Use Change and Land Markets (Floyd C. Corty, Louisiana State University)

"Evaluation of Land-Use Conversion: A Case Study of Land Subdivision For Recreational Housing on Virginia's Eastern Shore." Carl
Mabbs-Zeno and Sandra S. Batie, Virginia Polytechnic Institute and State University.

As part of a larger study which investigates net social benefit from various uses of coastal wetlands, this paper assesses marginal market value of converting wetland and fastland on the Eastern Shore of Virginia to recreational home lots. Data from a thousand lots sold in one subdivision were combined with cost estimates at that site indicating a $\$ 3,000$ per lot difference between marginal return to developers on wetland acreage over fastland acreage.

"Estimating Recreation Values Associated with Land Use Changes." Rod F. Ziemer and Wesley N. Musser, University of Georgia, Athens.

This paper presents a theoretical and empirical consideration of the relationships between land use and recreation demand, an issue which has received limited attention in the literature. Theoretically, the inclusion of certain land use variables in recreation demand equations is justified as a special case of the more general idea of considering the effect of recreational opportunity sets on demand, which has been cast in several theoretical frameworks. To test the hypothesis that land use change can affect recreation demand, an empirical model of big game hunting in Georgia which includes available forestland as an explanatory variable is presented. Standard methods of estimating consumer surplus from recreational models are then adapted to provide estimates of changes in consumer surplus arising from land use changes. These methods are applied to the empirical demand model in reference to recent reductions in forestland in Georgia. The loss in consumer surplus was estimated as $\$ 1.53$ per acre of forestland converted to other uses. This loss indicates that policies to maintain forestland probably could not have been justified on the basis of benefits to big game hunters alone.

"Classification and Analysis of Homogeneous Farmland Markets." Ivery D. Clifton, University of Georgia, Athens.

This paper uses a three stage analysis to classify and analyze counties in the United States among gradients of relatively homogeneous farm real estate submarket areas. The classification criterion is multivariate and uses a series of factors hypothesized to influence variations in farmland values. These factors are agricultural, economic, locational and demographic. Model results indicate that the nation's farmland can be segmented into 7 different but slightly overlapping submarkets. Density of population, median family income of blacks and whites, and proportion of land in farms are principal discriminators of the markets. Using these criteria, approximately 77 
percent of the U.S. counties were correctly classified to their respective markets.

"Analysis of Factors Affecting U.S. Farm Real Estate Vlaues." Larry D. Hauschen, Southeast Missouri State University and William McD. Herr, Southern Illinois University.

This study, by using a polynomial lag model (Almon lag), found that the major determinants of farm real estate values between 19391977 were net returns to farming, technological advancement, and nonfarm demand for farmland. The study concludes the expectations regarding income are based on incomes earned in the five previous years. Since 1970, farm enlargement and nonfarm demand have exerted relatively more impact on farm real estate values than in earlier years, while the impact of net farm income has diminished.

Beef Demand and Prices (Robert Raunikar, University of Georgia, Griffin)

"Hamburger Beef: Implications for the Southeastern U.S. Beef Industry." J. Richard Conner and Robert W. Rogers, Mississippi State University.

The proportion of United States beef consumption made up of ground beef has increased in recent years. With the impending cattle cycle induced decrease in the slaughter on non-fed cattle, the question arises as to how the demand for ground beef will be met. Two proposals have been advanced; to take more beef from the block-beef trade and to divert cattle from traditional feeding programs to "grow-out" programs which will produce beef exclusively for ground beef production. Since the latter proposal offers a possible attractive enterprise for Southern beef producers, the feasibility of both are evaluated. The evaluation consists of adopting a linear programming model to the beef market to examine the key relative price relationships between ground beef and other fed beef products at the wholesaler-processor level. The price of ground beef relative to the other beef products which allows fed beef primals to be diverted to ground beef is estimated. The shadow price of domestic deboned manufacturing beef is then used to derive a maximum price which could be paid for cattle from a "grow-out" program relative to the price of fed cattle. The results imply that the proposal to take beef from the block beef trade is feasible but the diversion of cattle to "grow-out" programs is generally impractical.
"Consumer Beef Preference." Alvin Schupp and Thomas Bidner, Louisiana State University.

Interest in producing consumer acceptable beef with much less fat has increased. Forage finished and limited grain finished steers produce beef with less fat. Marketability and consumer acceptability of beef from these steers was studied over a three year multi-phase project. Pasture, pasture with grain and short-tomoderate length feedlot finishing programs produced carcasses somewhat lower in quality grade than normal supermarket offerings.

Fat thickness increased and yield of closely trimmed retail cuts decreased as grain consumption increased. Most feeding treatment averaged USDA Good grade.

Test beef was marketed in supermarkets at small price discounts. Purchasers and members of household (consumer) panels rated the beef on tenderness, flavor, juiciness and overall acceptability. While purchasers and household panel members were able to distinguish some significant differences among feeding treatments, average ratings were numerically close for all treatments within phases. Treatment average ratings were in the upper half of the evaluation scale. Beef from pasture only finishing programs was fully acceptable to consumers when carcass weights exceeded 500 pounds.

Consumers were unwilling to pay higher prices for long fed beef. However, consumers expected palatability attributes accompanying moderate amounts of external fat.

"The Impact of Durable Goods Prices Upon Beef Demand." James N. Trapp and Phillip C. Hamilton, Oklahoma State University.

Inferences drawn from the fed and non-fed retail beef demand models reported in this study support the hypothesis that durable goods prices do affect beef demand. A positive relation was found to have existed between the quantity of high quality beef consumed and durable goods prices over the period 19711977. During the same period a negative relation was found between durable goods prices and the consumption of non-fed beef. The postulated basis for these relations rests upon two premises: first that high quality beef is a superior good and low quality beef is an inferior good; secondly that the short-run elasticity of demand for durable goods is elastic. Based upon these two premises it follows that when durable goods prices rise total expenditures for durable goods decline, leaving a larger amount of income to be spent on nondurable items, including beef. Such an increase in income available to purchase beef would be expected to influence beef demand in a manner 
similar to an increase in total income, i.e., positively for superior cuts of beef and negatively for inferior cuts. The results of this analysis provide statistical evidence that over the period 1971-1977 the preceeding premises and postulated results are correct.

"Forecasting Monthly Slaughter Cow Prices With a Subset Autoregressive Model." Thomas H. Spreen, Richard E. Mayer, James R. Simpson and James T. McClave, University of Florida.

Cow-calf operations dominate cattle production in the Southeast, and thus the receipts from the sale of cull cows represent an important source of income to Southeastern cattle producers. Cow slaughter can be volatile resulting in erratic prices. Cattle producers can both gain and lose from these erratic prices depending on when they choose to market.

A short-term price forecasting model for monthly Florida slaughter cow prices is presented in this paper. A subset autoregressive model is estimated using a procedure recently developed by McClave [10].

The estimated model is evaluated ex post and performed quite well in forecasting one, two and three months ahead. More distant forecasts of six, nine, twelve months ahead are less satisfactory, but the average forecast error of twelve month ahead forecasts is less than ten percent.

Methodology and Quantitative Methods (Garnett L. Bradford, University of Kentucky)

"Investigation of the Normality of Gross Revenues for Selected U.S. and South Carolina Crops." Gary J. Wells, Clemson University.

Criticism has been leveled against many risk models used to estimate cropping patterns. The general assumption made in incorporating risk into models is that the variables of interest are normally distributed. Argument is presented in this paper that if variables are not normally distributed identification of cropping patterns may not be successful.

Ten crops' gross returns per acre are investigated for normality. The aggregate U.S. and South Carolina levels are tested. Two methods of analysis are used. One method regressed gross returns against time and investigated the error. The other method employed the variate difference technique. The Shapiro-Wilk "W" test was used to test results of both methods for normality. Both methods showed evidence that many of the random portions of the variability of the gross returns are not normally distributed. They indicated that approximately seventy-five percent of the gross returns were not normally distributed when the systematic portion is removed.

Alternative methods of incorporating risk into models was briefly discussed. The methods discussed include; (1) possible further elaboration of Just's 1974 AJAE treatment of risk, (2) application of stochastic dominance conditions, and (3) transformation of variables to allow the traditional treatment as a normally distributed variable.

"A Recursive Interactive Goal Programming Model for the Analysis of Entry-Exit Coordination." Craig L. Dobbins, Purdue University and Harry P. Mapp, Oklahoma State University.

The purpose of this paper is to present a recursive interactive model comprised of goal programming and simulation components. The model is used to demonstrate, for an Oklahoma farm, the impact that alternative goal structures have on annual production plans and the financial position of the parents and son at the end of a 15 year entry-exit coordination plan. Results indicate that production plans under a ranked goal structure were more stable through time than those derived using a substitution goal structure. Net cash farm income under both goal structures was quite variable, although slightly less variable under the ranked goal structure. The trends in firm net worth were quite similar, however, there was a significant difference in the ending financial position of the son with the substitution goal structure providing a 34 percent larger net worth.

"Regional Acreage Response by Quarter for Fresh Tomatoes: An Example of the Use of Mixed Estimation." Michael D. Hammig, CED, ESCS, USDA, Washington, D.C.

An acreage planted relation was specified for quarterly and regional analysis of fresh tomato production. The specification included expected price, risk, costs of production, and lagged acreage as explantory variables. Eleven equations were estimated to represent total domestic annual production. All eleven equations were estimated by both OLS and mixed OLS regression.

Prior information from previous studies, economic theory, and subjective belief formed the basis of constraints imposed through the mixed estimation technique. Coefficients on expected price, risk and costs of production were subjected to probabilistic constraints.

OLS results revealed that eight of the eleven equations contained coefficients with signs contrary to accepted theoretical tenets. Many of the OLS coefficients were statistically insignificant. Mixed estimation results were substantially improved over OLS results. All 
signs of the mixed estimates were as anticipated. Furthermore only three of the mixed estimation coefficients had $t$ - values less than one.

Tests of compatibility between sample and prior information indicated insignificant difference in ten of the eleven cases. In the one case where compatibility was rejected, the mixed estimates were found to be superior in a strong mean square error sense.

"Determinants of Lender Response to ShortTerm Credit Needs." Steven T. Sonka and Bruce L. Dixon, University of Illinois.

Short-term credit needs play a crucial role in the growth and operation of the farm firm. A survey of 33 lenders in Illinois responding to three hypothetical loan situations is analyzed. Results employing logit analysis show that the liquidity position of the prospective borrower significantly influences the probability of credit being extended. In addition, the size of the lending institution is found to be positively associated with the probability of loan approval. A lender with an agricultural background is shown to be more likely to make a loan than a lender without such experience.

Regional Economics (James C. Hite, Clemson University)

"A Hypothesized Model for Explaining the Location and Expansion of Rural Industry with a Region." Dale Leuck, University of Tennessee.

An understanding of the national, regional, and community influences upon the location and subsequent expansion of industrial plants in rural communities is important to business and government leaders for policy purposes. Previous research on this subject has been lacking in sound theoretical foundations, which has led to empirical models that have been inappropriately specified and estimated. These specification and estimation problems are discussed and a theory and method of estimation are presented in order to minimize these problems.

"Interfacing Economic and Demographic Models for Rural Areas: Design and Methodology Considerations." Steve H. Murdock, F. Larry Leistritz and Lonnie L. Jones, Texas A\&M University.

The need to assess the impacts of resource and industrial developments in rural areas has led to increasing demands for computerized impact assessment models. These models, commonly referred to as "economic-demographic" assessment models, usually contain several component modules, but the essential integrating module is that which interrelates or interfaces the economic and demographic components. The paper discusses the essential characteristics of such interface components and describes one interfacing methodology that addresses these characteristics.

It is noted that interface procedures should: (1) be employed in both baseline and impact projections; (2) employ site and population specific data; (3) differentiate between various types of employment demands; (4) assess employment type specific local labor force availability and employability; (5) use employment type specific estimators of population characteristics.

The procedure described is employed in both baseline and impact local area projections and matches baseline, direct construction, direct operational and indirect employment demands with available employment for the same employment types. The matching of employment demands and availability by type determines required levels of migration by employment type. The application of worker type specific population rates to these migration requirements produces projections of total population. It is suggested that the procedure shows promise for further analysis and refinement.

\section{"Analysis of Rural Development Research Programs in the United States and Southern Region." Daniel Otto and Joseph Havlicek, Jr., Virginia Polytechnic Institute and State Uni- versity.}

An understanding of the allocation of research among regions, problem areas, and academic disciplines is essential to coordinating ongoing rural development research activities and setting the direction of future research programs. This paper uses data compiled from the Current Research Information System (CRIS) research abstracts for the entire U.S. to present and discuss the allocation of rural development research in the U.S. and the South.

The results show little difference between the research priorities of the South and the other three regions in the U.S. All regions concentrated their research in the human resource and economic development areas. A generally high degree of correlation (significant at the 5 percent level) was found between the level of rural development research funding in these areas and levels of rural population, education, income and unemployment. These results suggest that research funding is being allocated to states with apparent development needs.

Among the academic disciplines doing rural development research, agricultural economics 
was involved in 47.1 percent of the projects reported in the CRIS abstracts, followed by rural sociology departments which were involved in 17 percent of the projects.

"Aggregation and Specification Errors in Estimating Recreational Demand Models." Michael E. Wetzstein and John G. McNeely, Jr., University of Nevada.

Brown and Nawas have indicated that disaggretating observations in recreation demand analysis leads to gains in efficiency of estimates by reducing the degree of intercorrelation among variables. This paper suggests an alternative model specification for cases where disaggregation is not feasible or does not elevate a problem of multicollinearity. The results from this paper indicate that a model specification incorporating aggregated data over cost, rather than the traditional distance zone averages, provides a correct model specification without a relatively high degree of intercorrela tion between variables.

Public Services and Social Costs (Leroy Davis, Southern University)

"Impact of Medicare-Medicaid on the Spatial Distribution of Physicians." James R. Cantwell, EDD, ESCS, USDA, Washington, D.C.

One component of a strategy for economic development in Southern rural areas is to assure the availability of adequate health service to 1) improve the productivity of present workers, 2) stimulate entrance of producers who will add to the region's export base, and 3) through an import substitution process, generate local physician service-based incomes to which a traditional multiplier will apply.

This study explores the impact of two large public sector health insurance programsMedicare and Medicaid-on the spatial distribution of physicians. It is argued that the increase in overall demand for physician services which resulted from these programs made it more difficult to attract physicians to shortage areas. Not only are there 132 nonmetropolitan counties, including 59 Southern counties, without an active physician but it is shown in the paper that the trend is toward relative fewer physicians in small nonmetropolitan areas. (The population/physician ratio has risen since 1940 in nonmetropolitan counties with fewer than 25,000 population.)

“The 'Program for Better Jobs and Income' and the Distribution of Welfare Benefits in the South." Shirley Pryor, EDD, ESCS, USDA, Washington, D.C.

Any change in the current welfare program would have a substantial effect on the South because of its large poverty population. A micro-simulation model of U.S. transfer income and tax program was used to evaluate and compare the regional and residential distribution of benefits under the current welfare system with the Carter Administration's welfare proposal "Program for Better Jobs and Income" (PBJI). PBJI would especially affect the South because of the provisions for instituting a national minimum benefit level and extending cash benefits to different family types not currently fully covered by the existing welfare system.

The amount of benefits and the number of eligibles would increase substantially in the South. Average benefits in the South and the non-South and in metropolitan areas and nonmetropolitan areas would become more similar with average benefits increasing in the South in both metropolitan and nonmetropolitan areas and decreasing in the non-South.

PBJI would make the distribution of families of eligible for welfare similar to that of the needy population. PBJI would also reduce the number of people below the poverty level in all regions and places of residence compared to the current system. Although there would still be a substantial percent of people in poverty in the nonmetropolitan South (14.6\%) with PBJI, the greatest drop in poverty would occur in that area. The greatest drop in metropolitan poverty would be the non-South, where 7.3 percent would remain in poverty. In the metropolitan South, 10 percent would remain in poverty with PBJI.

"Impact of Alternative Welfare Reform Proposals by Regions of the County." G. William Hoagland, U.S. Congressional and Budget Office, Washington, D.C.

Four major welfare reform proposals were debated in the recent 95th Congress. These proposals were: (1) Administration's Program for Better Jobs and Income, (2) a special House Welfare Reform Subcommittee proposal, (3) a proposal introduced by Senators Baker and Bellmon, and (4) a proposal developed by Congressman Ullman. The proposals were analyzed as to their potential impact on the reduction of state and local welfare costs and on the reduction in the incidence of poverty. Particular attention was given to the proposals' impact on the South. Overall, the Baker-Bellmon proposal would have resulted in nearly a $\mathbf{4 7}$ percent reduction in welfare expenditures for the South, while also reducing the incidence of poverty by about 11 percent in that region. The Administration's proposal would have reduced welfare expenditures in the South by 25 percent, and would have resulted in nearly a 26 percent reduction in the incidence of poverty. The special Welfare Reform Subcommittee 
proposal and the Ullman proposal would have provided little fiscal relief for the South, the latter proposal even resulting in some increased costs. The incidence of poverty would have declined by approximately 20 percent in the South under these latter two proposals.

"A Theoretical Framework for Analyzing Social Costs of the Tobacco Program." Ruth C. Johnson and Ben R. McManus, University of Tennessee.

Social costs are defined as: (1) loss of consumer and producer surplus and (2) public costs in excess of private costs. Health-related public costs of tobacco represent a social cost. The present output and price of tobacco are compared with an estimated competitive market equilibrium and a hypothetical full-cost equilibrium in which public costs are incorporated in the supply curve. Output restriction under the tobacco program results in a net loss of consumer and producer surplus. At the same time, public social costs of tobacco are reduced. The reduction in social costs exceeds the loss of consumer and producer surplus under the assumptions and conditions evaluated.

Mathematical methods for measuring social costs are illustrated. Empirical estimates of public social costs of tobacco are needed for quantitative measurements. The framework has application to policy analysis with respect to current issues when social costs are involved.

Supply Response (Ben R. McManus, University of Tennessee)

"Alternative Scenarios for the United States Pecan Industry." John R. Allison and James E. Epperson, University of Georgia, Griffin.

The pecan producing industry may well be headed into an era of increased price uncertainty in light of recent innovations in high yielding technology, a leveling of the declining trend in bearing trees, a recent upward trend in nonbearing trees, and a declining per capita consumption of pecans. The events portend the potential for significant downward price adjustments at the farm level in the near future.

The purpose of this paper is to project future production for the pecan producing industry and ascertain the impact on farm-level price. Three scenarios predicting production of pecans for 1985 are presented. A price determination model is depicted which predicts the price of pecans given predetermined quantities.

Results from the scenario analysis indicate the future deflated price adjustments will not be as severe as suspected. Supplies of inshell pecans are expected to be larger by 1985 ; however, the resulting downward pressure on price 186 is expected to impact more as an anchoring effect on price increases than as a major cause for significant reductions in price.

"Production Responses and Price Determination in the Florida Watermelon Industry." G. Bryan Wall and Daniel S. Tilley, University of Florida.

A conceptual and empirical model for the marketing of Florida produced watermelons is presented to explain cob-web type fluctuation in production. The effect of competing states production on Florida prices, is also shown. Current and lagged acreage response coefficients, price flexibilities, and the relationship between the effect of prices on harvest decisions as a function of planting levels are also presented.

"Market Imperfections in the Lease and Transfer of Burley Tobacco Quotas." Mary C. Kennedy, NEAD, ESCS, USDA, Washington D.C. and D. Milton Shuffett, University of Kentucky.

Since the inception of the intra-county lease and transfer provision of the Burley Tobacco Allotment Program, producers have participated in the leasing market at an increasing rate. This study is designed to provide some insight with respect to the market for burley tobacco leases.

Demographic characteristics of 102 Kentucky counties are related both to current annual price as well as to quantities transferred. Price appears to be more closely associated with the selected characteristics than does quantity transferred, which appears to be relatively constant.

Questionnaires were mailed to all leasing participants in three counties requesting information not available publicly. Rounded prices are noted in 87 percent of the questionnaire responses. Leasing within a county results in movement of quota from less productive to more productive areas, and from smaller units to larger more commercialized units.

It is concluded that inter-county leasing has the potential for reducing the rigidities inherent in the allotment distribution, leading to greater productive efficiency. A mechanism for handling such transfers does not currently exist.

Pricing Policies (Richard L. Kilmer, University of Florida)

"An Analysis of the Income Effect on Whole Milk and Low Fat Milk Consumption." ChungLiang Huang and Robert Raunikar, University of Georgia, Griffin.

This paper postulates that the demand for whole milk and low fat milk may change as 
household income changes. The objective of the study was to test this hypothesis, and to analyze the consumption patterns for two types of fluid milk among income levels. The study utilizes the weekly purchases data collected from a consumer panel consisting of about 120 reporting households in Griffin, Georgia, during the 1975-1976 period. The ordinary least squares procedure was applied to a modified hyperbolic function to estimate the effects of variations in income on consumption of the milk types. Income elasticities were estimated by levels of income to reflect changes in consumption of each milk type as household income changes.

The results indicate that whole milk was selected over low fat milk at low income level. However, low fact milk was increasingly substituted for whole milk as household income increases to the level of approximately $\$ 7,130$. These findings suggest that market segments for specific milk types may be defined by household income levels. Therefore, in planning marketing strategies, the dairy industry should consider the income classes as different markets for the two types of fluid milk products.

"Milk Pricing and Economic Formulas." Art Smith, CMPD, ESCS, USDA, Washington, D.C. and Ronald D. Knutson, Texas A\&M University.

In recent years criticism has been directed toward the utilization of the Minnesota-Wisconsin price series as the base for the minimum Class I price in the Federal milk marketing order system. The means of setting the Class I price is important to producers in the South as that price is most important in determining the blend price they receive.

Economic formulas have been proposed as a means of pricing Class I milk. The process of developing economic formulas has been one of conjecture, consensus and compromise and the use of such unobjective procedures is reflected in their poor performance.

Developed from this study is a methodological process by which an economic formula may be determined. Factors which influence milk prices are determined by their role as either supply or demand shifters in an economic model of the dairy industry. The uniqueness or the Federal order pricing system requires an objective function which will maintain producers' returns without supply control. Factor weights are then determined through the mathematics of comparative statics. The result is a linear economic formula which embodies properties of equilibrium.
"Importance of Understanding Consumption Dynamics in Market Recovery Periods." Daniel S. Tilley, University of Florida.

Periods of short supply of orange juice caused by freezes are generally associated with high retail prices. Understanding consumers' responses to these events requires recognition of sources of rigidites that cause delays in consumer responses. Dynamic demand relationships for frozen concentrated orange juice (FCOJ) and chilled orange juice (COJ) are estimated. The importance of product characteristics in determining whether habit or stock effects dominate is demonstrated. FCOJ exhibits inventory dominance while COJ exhibits habit dominance. In addition, the relative importance of rigidities in percentage of families buying and ounces per buying is also determined and reported. The implications of the models for the 1978-79 season are developed and presented.

Natural Resource Policy (Ronald D. Lacewell, Texas A\&M University)

"An Evaluation of the Economic Impact of Section 208 on Cotton and Soybean Production in the Mississippi Delta Area, 1978." Cleveland $H$. Marsh and D. W. Parvin, Mississippi State University.

The economic impact of Section 208, PL952000 on agricultural production is largely unexplored. Soil erosion controls under the new law will significantly change the way cotton and soybeans are grown in the Mississippi Delta. Section 208 will result in a small reduction in acreage presently involved in agricultural production, acreage shifts from cotton to soybeans, and a significant decrease in net returns to producers. Long run effects include losses of $\$ 332$ million and 37,400 jobs throughout the trade region.

"Strip-Mine Reclamation Laws and Regional Cost Incidence." Lowell B. Catlett, New Mexico State University and Michael D. Boehlje, Iowa State University.

Recent state laws and the new federal law, Public Law 95-87, require "back-to-original" reclamation for strip-mined land. The new federal law also requires miners to estimate "back-to-original" reclamation costs before a permit will be issued. A cost function developed under "back-to-original" criterion shows the average reclamation cost per ton of mined coal to be $\$ 6.92$ in Appalachia, $\$ 6.02$ in the Midwest and $\$ 1.01$ in the Mountain West. Total United States costs to meet the requirements of "back-to-original" reclamation will be over two billion dollars with Appalachia's 
share being 1.2 billion dollars. Under a scenario that doubles present production levels, total U.S. costs jump to almost three billion dollars and Appalachia's to over 1.5 billion dollars. Appalachia suffers the largest regional incidence of the new law by disturbing only 98,000 acres (31 percent of U.S. total), but spending 1.5 billion dollars (51 percent of the U.S. total).

"Local Impacts of Soil Conservation Strategies for a Large River Basin in the Southeast." Clayton W. Ogg, Ralph E. Heimlich, and John E. Hostetler, NRED, ESCS, USDA, Broomall, Pennsylvania.

Reducing erosion related nonpoint pollution from agriculture may require changing the location of row crop production as well as application of conservation practices where crops are grown. A linear programming model is used to project crop location changes and the cost and erosion impacts of minimum cost soil conservation strategies for a large river basin in the Southeast. Computer maps display land use changes under one hypothetical river basin plan. Model solutions clarify the role of conservation practices in carrying out new national environmental programs. It is argued that Clean Water Program subsidies can lead to implementation of the most efficient plans once conservation and water quality goals are determined.

Pest and Disease Management (Robert N. Shulstad, University of Arkansas)

"An Illustration of Economic Decision Making Using Applescab: A Biological Pest Management Simulation Game." Kenneth H. Baum and Ronald W. Tillman, Virginia Polytechnic Institute and State University.

A biological simulation game, APPLESCAB, was used to illustrate the economic impact of various pest management strategies on the net income of an apple producer. The apple scab disease is caused th the fungus Venturia inaequalis. The simulation game was first utilized to empirically demonstrate how maximum profits occur when the returns from the pest management program equal the costs of the fungicide spray despite the discreteness of applications. The game was then played with four pest management strategies under various weather regimes. The resulting data supported the hypothesis that optimal pest management and larger profits occur when the producer explicitly recognizes that the peak pest infestation level should exceed the damage threshold when there are positive incremental costs of pest control. Ultimately, the final choice of pest management strategy by the producer will depend in large part on his willingness and ability to take risk and on his perception of the growing season's expected weather regime.

"An Economic Impact Evaluation of Government Programs: The Case of Brucellosis Control in the United States." Chun-Lan Liu, NEAD, ESCS, USDA, Washington, D.C.

This paper provides ex ante estimates of the social value of the USDA's program alternatives for controlling brucellosis over a 23-year planning horizon to year 2000. The objectives of the program are to contain and eradicate brucellosis, a disease which reduces beef and dairy production. Results indicate that controlling brucellosis causes a positive supply response, higher production and lower commodity prices. Consumers benefit from the larger production and lower prices. Producer's benefits decrease as the program alternatives move toward eradication but increasing consumer benefits more than offset decreasing producer benefits and program costs for a net social gain.

"The Stochastic Impacts of a Ban of Toxaphene for the Budworm-Bollworm Pest Complex in Cotton." Reuben N. Weisz, NRED, ESCS, USDA, Ronald R. Miller, Department of Energy, and William Quinby, NRED, ESCS, USDA, Washington, D.C.

A methodology for evaluating the stochastic impacts of pesticide regulations is presented in this paper. Our analysis of a ban on toxaphene for the budworm-bollworm pest complex in cotton gives the following results:

A ban would increase the average price of cotton as well as its price instability. It would decrease the level and increase the variability of yield and production. It should decrease the expected value, but not the variance of exports.

These results are based on an analysis of preliminary data developed by the USDA/EPA Assessment Team. However, the Monte Carlo driven economic simulation model used here should be applicable in future technology impact policy analyses where more refined data are available. The model evaluates a broader range of possible outcomes than is available through a deterministic analysis. It allows the researcher to evaluate the probability of outcomes instead of relying on mere point estimates. 